\title{
A case of post-ablation-tubal sterilisation syndrome
}

Published online: 25 May 2005

(C) Springer-Verlag Berlin / Heidelberg 2005

\section{Case report}

A 36-year-old married woman was referred by her GP in July 2000 with a long-standing history of menorrhagia. Treatment with Provera and oral contraception had shown limited success. She was requesting a more permanent solution.

This patient was parous and had completed her family. Her cycle was regular on the oral contraceptive pill (OCP, Logynon). She was counselled and underwent a transcervical resection of the endometrium (TCRE) using a hysteroresectoscope and rollerball diathermy. This was combined with laparoscopic sterilisation using Fallope tubal rings. She was reviewed at three months and found to be asymptomatic and amenorrhoeic. She was, therefore, discharged back to her GP.

In July 2002, 18 months after the initial surgery, she was referred again by her GP with a 6-month history of increasing right iliac fossa (RIF) tenderness. The pain was of a cyclical nature and was associated with a very slight menstrual loss. A transvaginal ultrasound scan revealed the presence of a small haematometra $(1.2-\mathrm{cm}$ diameter) towards the right cornua of the uterus, consistent with a diagnosis of cryptomenorrhoea. There were no adnexal masses and her ovaries were normal.

A diagnosis of uterine stenosis and haematometra was made and, in October 2002, she underwent an examination under anaesthesia (EUA), cervical dilatation and insertion of a NovaT intrauterine contraceptive device (IUCD) to prevent restenosis. A hysteroscopy was not considered necessary at this stage in the view of clinical and ultrasound evidence of cryptomenorrhoea. Moreover, hysteroscopy is often unrewarding in postoperative assessment due to the presence of intracavity adhesions, which the make detection of endometrial tissue difficult or impossible, even in patients who con-

J. E. Martín $(\bowtie) \cdot$ T. C. M. Inglis

115 Upper Chorlton Road, Manchester, Lancashire, M16 7RY, UK

E-mail: pepekike@tiscali.co.uk tinue to menstruate [1]. Six weeks later, she was reviewed in the outpatients clinic. Her RIF pain was still present, but to a lesser degree, and she was given oral analgesics and then discharged.

However, in January 2003, she was referred once again with the same right-sided cyclical pain. This was now severe in nature for 2-5 days of every month. She was listed for a diagnostic laparoscopy and advised to take the OCP continuously in the interim.

At laparoscopy, the uterus and ovaries were found to be normal. There was no evidence of endometriosis or adhesions. The left fallopian tube appeared normal, apart from previous sterilisation with the Fallope ring. However, the right fallopian tube showed haematosalpinx of the proximal stump up to the level of the Fallope ring, which was "in situ." The right uterine cornua was also swollen and coloured blue. Monopolar diathermy was applied to the tubal remnant and the cornual end.

At the 6 weeks and three months review, she remained asymptomatic and was discharged from hospital care.

\section{Discussion}

In 1948, Baumann described the first successful ablation of the endometrium [2]. In 1981, Goldrath reported the first effective ablation under direct hysteroscopic vision using a laser [3]. Endometrial ablation for the treatment of menorrhagia was introduced in the UK in 1988 [4]. Since then, several methods of endometrial ablation have been developed using laser, diathermy, radiofrequency, microwaves and hot water balloons. These methods have been demonstrated to be safe and of similar effectiveness. They preserve the uterus and are associated with low peri-operative morbidity and relative low cost when compared with hysterectomy [5].

TCRE/endometrial ablation has been shown to be an effective method of treating women with menorrhagia [6-8]. When counselling a woman prior to TCRE, the reduction in the flow and duration of periods should be 
stressed, rather than amenorrhoea. Endometrial tissue has a tendency to persist or regenerate, in particular, in the cornual or intramural tubal areas [9]. Turnbull et al. [1] demonstrated that $95 \%$ of women have cornual endometrial tissue present and $18 \%$ have cornual haematometra determined from a magnetic resonance imaging (MRI) scan. In this study of 59 patients, 11 of them $(18 \%)$ had haematometra from an MRI scan and cyclical pain was described in 29 patients $(50 \%)$. However, Turnbull does not specify whether the presence of haematometra was associated with pain or not.

Women who present to their gynaecologists complaining of excessive menstrual loss are, by definition, able to become pregnant. If, subsequently, they are offered endometrial ablation, one can only assume that they have already completed their families and, therefore, will also need some form of contraception. It is for this reason that women who are not already sterilised are offered concomitant sterilisation.

Post-ablation-tubal sterilisation syndrome was first described by Townsend et al. [10] and confirmed by Webb et al. [11]. It is a delayed complication following endometrial resection/ablation in women who have had tubal sterilisation procedures. Classically, lower abdominal pain and vaginal spotting occur typically 490 months after ablation [9]. The pain is usually cyclical in nature and may be either bilateral or unilateral. The pathophysiology is probably that of regeneration of endometrium in the cornual area. As the lower uterine segment is often scarred extensively, menstrual blood is forced out into the fallopian tube, filling the proximal tubal stump with blood. The resultant distension causes the described symptoms [10]. The incidence of this syndrome is reported in between $6 \%$ and $10 \%$ of cases [9] when both sterilisation and ablation were performed.

It has been suggested that all patients presenting with these symptoms following endometrial resection/ablation and sterilisation should be assessed laparoscopically during menstruation to evaluate the possibility of retrograde menstruation dilating the proximal tubal stumps [12]. Furthermore, the risk of this complication should probably be discussed with women pre-operatively.

Unless contraindicated, a trial of non-steroidal antiinflammatory medication or oral contraceptives would be a reasonable initial treatment of this condition [9]. Otherwise hysteroscopic drainage of the cornual haematometra should ensue. This is a difficult procedure because intrauterine adhesions make it difficult to approach the cornual area without the danger of perforation [9]. If this fails or if the condition recurs, release of the haematosalpinx can be achieved by laparoscopic diathermy to the tubal stump, as in our case. Unilateral laparoscopic salpingectomy has also been recommended as a treatment alternative since the cyclical pain in these cases is likely to be due to tubal distention. However, a bilateral procedure may be more appropriate, since recurrence in the remaining tube has also been described [10]. A definitive treatment would be a hysterectomy.
Histological confirmation of post-ablation-tubal sterilisation syndrome requires assessment of the cornual tissue and proximal tube [13].

How can post-ablation-tubal sterilisation syndrome be prevented? Sufficient ablation of the cornual area can be attempted. This, however, carries the risk of cornual perforation. Alternatively, sterilisation could be performed as close as possible to the cornual area to avoid haematosalpinges formation, but this will not prevent the formation of cornual haematometra. McCausland and McCausland [14] propose partial rollerball endometrial ablation, where only the anterior or the posterior endometrial wall is ablated and the cornual areas are specifically avoided. They claim no post-ablation-tubal sterilisation syndrome or cornual haematometra in over 1,000 cases after 5 years follow-up. Their goal however is hypomenorrhoea, not amenorrhoea. This technique needs further assessment. Newer techniques of endometrial ablation (thermal ablation, microwave) may cause less scarring and less cases of cryptomenorrhoea. However, further evaluation regarding complication rates for these techniques is needed.

\section{References}

1. Turnbull LW, Bowsley SJ, Horsman A (1997) Magnetic resonance imaging of the uterus after endometrial resection. $\mathrm{Br} \mathbf{J}$ Obstet Gynaecol 104:934-938

2. Baumann A (1948) Electrocoagulation of endometrium and cervical mucosa (for uterine hemorrhage and leukorrhea). Geburtshilfe Frauenheilk 8:221-226

3. Goldrath MH, Fuller TA, Segal S (1981) Laser vaporization of the endometrium for the treatment of menorrhagia. Am J Obstet Gynecol 140:14-19

4. Magos A (1990) Management of menorrhagia: hysteroscopic techniques offer a revolution in treatment. Brit Med J 300:1537-1538

5. Garry R (1997) Endometrial ablation and resection: validation of a new surgical concept. Br J Obstet Gynaecol 104:1329-1331

6. Pinion SB, Parkin DE, Abramovich DR, Naji A, Alexander DA, Russell IT, Kitchener HC (1994) Randomised trial of hysterectomy, endometrial laser ablation and transcervical endometrial resection for dysfunctional uterine bleeding. Brit Med J 309:979-983

7. O'Connor H, Broadbent JA, Magos AL, McPherson K (1997) Medical Research Council randomised trial of endometrial resection versus hysterectomy in management of menorrhagia. Lancet 104:601-607

8. Overton C, Hargreaves J, Maresh M (1997) A national audit of endometrial destruction for menstrual disorders: complication rates for different techniques. The MISTLETOE study. Br J Obstet Gynaecol 104:1351-1359

9. McCausland AM, McCausland VM (2002) Frequency of symptomatic curnual hematometra and postablation tubal sterilization syndrome after total rollerball endometrial ablation: a 10-year follow-up. Am J Obstet Gynecol 186:1274-1280

10. Townsend DE, McCausland VM, McCausland AM (1993) Post-ablation-tubal sterilization syndrome. Obstet Gynecol 82:422-424

11. Webb JC, Bush MR, Wood MD, Park GS (1996) Hematosalpinx with pelvic pain after endometrial ablation confirms the post-ablation-tubal sterilization syndrome. J Am Assoc Gynecol Laparosc 3:419-421

12. Morrissey K, Idriss N, Nieman L, Winkel C, Stratton P (2002) Dysmenorrhea after bilateral tubal ligation: a case of retrograde menstruation. Obstet Gynecol 100:1065-1067 
13. McCausland VM, McCausland AM, Van Voorhis B (2003) Previous tubal ligation is a risk factor for hysterectomy after rollerball endometrial ablation. Obstet Gynecol 101:818-819

14. McCausland AM, McCausland VM (1999) Partial rollerball endometrial ablation: a modification of total ablation to treat menorrhagia without causing complications from intrauterine adhesions. Am J Obstet Gynecol 180:1512-1521 